\title{
A STUDY OF THE AQUATIC INSECTS OF TWO ROCKY MOUNTAIN STREAMS IN GRAND TETON NATIONAL PARK
}

\author{
Donald V. Bennett \\ Department of Entomology, Fisheries and Wildlife \\ University of Minnesota, St. Paul, MN 35108
}

\section{Introduction}

An investigation of the insect faunas of Pilgrim and Pacific Creeks was carried out for comparison and contrast of the two streams. The possibility of placer mining at Pacific Creek emphasized the need of the study at this point in time. Systematic collection of insects and physical data from the streams provide information on habitats which are essentially unaltered by man. It is hoped that this research will form the groundwork for future studies and provide data for reference in the event of ecological disturbance of either habitat.

\section{Methods}

The techniques for measurement of water chemistry were taken from 0.T. Lind's Handbook of Common Methods in Limnology (1974). The hydrogenion concentrations were determined with a portable electric pH meter. Free $\mathrm{CO}_{2}$ was calculated from the $\mathrm{pH}$ and total alkalinity using the formula $\mathrm{mg} \mathrm{CO} / 1=1.589 \times 10^{6}\left(\mathrm{H}^{+}\right) \times \mathrm{mg} / 1$ alkalinity. Dissolved oxygen was derived from the azide midification of the Winkler method. Alkalinity was measured with bromcresol green - methyl red indicator and $.02 \mathrm{~N}$ sulfuric acid. A portable electric meter was used to determine conductance. Current was taken at each sample location with a Weather Measure pygmy current meter at $4 \mathrm{~cm}$. above the substrate. Temperature was recorded with recording thermometers and mercury thermometers. Benthos was collected with a $.1 \mathrm{~m}^{2}$ modified Waters and Knapp sampler. The collecting nets mesh openings were $.505 \mathrm{~mm}$. A stratified random sampling regime was used so that the most diverse array of habitats could be collected with the fewest number of samples. A pool, medium riffle, and fast riffle was sampled on every collection date in each stream. A grid was superimposed over each area and the coordinates drawn randomly for each collection. The depth, surface temperature, and current were taken at each collection. Current measurements were taken close to the substrate as suggested by Cummins (1962). The larger stones were cleaned and removed from the sampler. The remaining sand and gravel was stirred to a depth of $15 \mathrm{~cm}$. for 3 to 5 minutes. The samples were then picked at $15 x$ under a dissecting scope and sorted to operational taxa. Head capsule and length were measured for the first 20 organisms in a taxon and only lengths for the remaining individuals. The insects were refrigerated and kept on ice during this process. Wet weights were taken after drying on filter paper. The insects were dried in 1 dram vials at a temperature of $30^{\circ} \mathrm{C}$ 
for at least 48 hours. Dry weights were then taken. It is the authors opinion that in future studies two meters should be used to determine $\mathrm{pH}$ in order to obtain a mean and variance,

\section{RESULTS AND DISCUSSION}

\section{Physical Description of Pilgrim and Pacific Creeks}

Pilgrim and Pacific Creeks are fourth order streams in northwestern Wyoming on the western side of the continental divide. Pacific Creek flows southwest. It starts almost at the continental divide with a water shed encompassing parts of the Washakie Mountain Range and the Pinyon Peak Highlands. It flows into the Snake River approximately 7 kilometers downstream of the Jackson Lake Dam. Pilgrim Creek is about $10 \mathrm{~km}$ north of Pacific Creek, and flows south southwest from the Pinyon Peak Highlands into Jackson Lake. Pilgrim Creek is two-thirds the length of Pacific Creek and has a proportional amount of water flowing in it. The collection site at Pacific Creek was at approximately $2040 \mathrm{~m}$ in elevation and the site on Pilgrim Creek at $2070 \mathrm{~m}$. Both streams have broad outwash plains formed by post-glacial down-cutting through the gravel deposited by Jackson Lake Glacier. Their substrate is formed from igneous rock and comprised of cobble and gravel in a sand base. The streams commonly meander forming two or more channels exhibiting a braide- morphology. There is a well defined terrace which separates the dominant plant communities from the riverbed plant communities. Willows (Salix spp.),alder (Alnus tenuifolia), narrowleaf cottonwood (Populus angustifolia), and silverberry (Eleagnus commutata) are common within the outwash plain. The streamside ecotone of Pacific Creek is characterized by narrowleaf cottonwood, blue spruce ( $P$ icea Pungens), russet buffaloberry (Shepherdia canadensis), Ribes spp., and honeysuckle (Lonicera involucrata). The vegetation is similar at Pilgrim Creek with the addition of balsam poplar (Populus balsamifera) as a codominant species with the cottonwood and blue spruce. The streams both travel through all the major plant communities of the area from alpine to big sagebrush (Artemisia tridentata), aspen (Populus tremuloides), and lodgepole pine (Pinus contorta)forests.

Seasonal variation in the streams is marked and relatively fast. They vary from flood stages in May - June to moderately flowing streams in September. Pacific Creeks water level dropped $10 \mathrm{~cm}$ from early July to late August. Pilgrim Creek dropped $7.5 \mathrm{~cm}$ in a comparable time period. The drop in water level had a greater effect on the width of Pilgrim Creek ( $6 \mathrm{~m}$ to $3.6 \mathrm{~m}$ in the fast riffle sample area) than in Pacific Creek $(16.5 \mathrm{~m}$ to $14,4 \mathrm{~m}$ in the fast riffle sample area) because of the overall size of the two streams. The current in the medium riffle in Pilgrim Creek varied from $.418 \mathrm{~m} / \mathrm{sec}(75 \mathrm{~cm}$ from the bank) on July 7 to $.169 \mathrm{~m} / \mathrm{sec}$ on September 8. Pacific Creek varied similarly with a current speed of $.371 \mathrm{~m} / \mathrm{sec}$ on July $14(175 \mathrm{~cm}$ from the bank) to $.208 \mathrm{~m} / \mathrm{sec}$ on July 27 ( $25 \mathrm{~cm}$ from the bank). The water chemistry of the two streams changed synchronously with the variation in the streamsfflow. The change over from mainly snow melt runoff 
to a ground water-and precipitation-dependent water supply created corresponding changes in the water chemistry. From Fig. 1 it can be seen that the $\mathrm{pH}$ in Pacific Creek rose $.6 \mathrm{pH}$ units from July 14 to August 9. Pilgrim Creek had a fairly stable pH by July 23 , but a pH reading of 8.3 taken on July 7 th implies an increase towards the base end of the spectrum throughout the spring. The $\mathrm{pH}$ of these streams is alkaline in comparison to a mode of 7.9 found amoung 14 Rocky Mountain streams west of the Continental Divide (Pennak, 1977). In addition to the change in water sources the increasing $\mathrm{pH}$ could also be accounted for by greater photosynthetic activity of the algae which accumulated steadily after spring runoff. Generally it can be seen that Pilgrim Creek had a higher $\mathrm{pH}$ than Pacific Creek. This accounts for the greater amount of dissolved $\mathrm{CO}_{2}$ in Pacific Creek. It is assumed if the $\mathrm{pH}$ is above 8.3 there is no free analytic $\mathrm{CO}_{2}$, whereas if it is below 8.3 then gaseous $\mathrm{CO}_{2}$ should occur in company with bicarbonate ions. In this case the free $\mathrm{CO}_{2}$ is simply a reflection of the $\mathrm{pH}$ and alkalinity. 1 feel the drop in free $\mathrm{CO}_{2}$ in Pacific Creek is an indication of the increased photosynthesis of the accumulating algal population in the stream. Inversely, as the plants assimilate the $\mathrm{CO}_{2}$, oxygen is released into the water. This is confirmed by the gradual increase in dissolved $\mathrm{O}_{2}$ seen throughout the summer. The low oxygen concentration in Pacific Creek on August 9 could be explained by overcast rainy weather for 3 days preceding the water analysis.

The total alkalinity (highest reading $91 \mathrm{mg} 6 \mathrm{CaCO}_{3} / 1$ at Pacific Creek) represents hard water, and indicates the creeks probably flow through some sedimentary rocks farther upstream. It increased throughout the summer. Pennak (1977) found similar changes in 20 Rocky Mountain streams. He attributed the increase to the fact that during the high flow of the spring runoff the water has little time to pick up soluble materials from the substrate. As the flow decreases, the water remains in contact with the substrate longer, dissolving more soluble materials. This results in a gradual increase in alkalinity as the season progresses as was observed in Pilgrim and Pacific Creeks. The total dissolved solids (TDS) were not measured. The increase in conductance through out the summer does infer a corresponding increase in TDS. Little is known about the correlation between TDS (due to a river influent) supported a commerical fishery, whereas, Great Bear Lake with a lower TDS (no large influent) could not support a fishery.

The temperatures recorded show minor variation throughout the summer. Temperatures taken from a 1 meter deep, fast flowing portion of the stream ranged from $1-2.2^{\circ} \mathrm{C}$ in a 24 hour period. The range in Pacific Creek was from $13.5^{\circ} \mathrm{C}$ on July 23 to daily peaks of $16.5^{\circ} \mathrm{C}$ throughout late August and early September. Pilgrim Creek ranged from $15^{\circ} \mathrm{C}$ on July 8 th to peaks of $17^{\circ} \mathrm{C}$ during mid-August to early September. Temperatures were also recorded from $5 \mathrm{~cm}$ below the water surface at each sampling site. These records varied as much as $1.75^{\circ} \mathrm{C}$ between sites on a given day and were usually $1^{\circ} \mathrm{C}$ higher than the temperatures on the recording thermometers. 
The Insects of Pilgrim and Pacific Creeks

Table 1 lists the insects collected from the streams in quantitative samples taken during the summer of 1979. The two streams were collected on alternate weeks. The data are presented in chronological order in all tables. This is done because of the similarity of the bottom faunas in the two streams. It is easy to discern the length of time during which a given insect taxa is represented in the samples. The occurance of the organism in one or both streams is also easily noted. A small case letter e has been used to show that general adults were collected on that date. The stream bank, margin, and surface dwelling insects are poorly represented in this table. Dip net collections yielded surface-dwelling species such as: Gerris remiges, G. dissortis, G. incurvatus (water striders), Microvelia buenoi (small water striders), Gyrinus confinus, G. affinis, G. picipes, and G. pleuralis (Wirigig beetles). Dip net collections along and under the streambank yielded: Cenocoriza bifida, Sigara omani, Callicoriza audeni (water boatmen), Amphizoa sp. (trout stream beetles), Acilius abbreviatus, Colymbetes exaratus, Rhantus binotatus, Agabus ericksoni, Hydroporus (Oreodytes) crassulus, H. rivalis (predacious diving beetles), and Notonecta kirbyi (backswimmers). Faunal successions with changes in elevation are also to be expected (see Allan, 1975). Collections at higher elevations produced different species such as the perlid stoneflies Claasenia sabulosa and Doroneuria theodora. The number of genera collected in each sample separated by habitat is recorded in Table 3 as a means of assessing species richness. Addition of Chironomid genera would probably increase these numbers on the order of 2-7 in each collection. Although some genera may have 5 species and others only 1 it is felt that analysis at this level is the most accurate. It eliminates quessing species numbers in taxonomically difficult groups. A Shannon-Wiener species diversity index was not calculated due to the aforementioned reason and the arguments of Hurlbert (1971).

It appears as though the fast riffles support the largest number of species, whereas the medium riffles support the fewest. One explanation for this is the relative instability of the medium riffle throughout the season. The fast riffles drying up during the autumn. The effects of substrate and its changes on macrobenthos is well documented in Cummins and Lauff (1969) and De March (1976).

By averaging the mean biomass from all collections it can be seen that the biomass in Pacific Creek is Approximately $1 \frac{1}{2}$ times that found in Pilgrim Creek, (Table 3). This is to be expected when comparing size and stability of the water bodies. The biomass increased in both streams from July through September, although the data in Table 3 doesn't show a consistent increase. This can be explained by the collection of last instar Tipulids (accounting for $1.04 \mathrm{~g}$ in the pool at Pacific Creek on July 14) and large stoneflies (accounting for almost $.5 \mathrm{~g}$ in the fast riffle at Pacific Creek on July 30). A more consistent increase is found in the number of individuals through 
the summer and fall. If the numbers of individuals and biomass of the two streams are compared with the "food grade"! of Davis (1938) Pilgrim and Pacific Creeks are rich in numbers (greater than 2152 organisms $/ \mathrm{m}^{2}$ ) and poor in biomass (less than $11 \mathrm{~g} / \mathrm{m}^{2}$ ). Compared to the numbers of organisms Pennak (1977) found in 20 Rocky Mountain trout streams, the creeks examined in this study are densely populated. This discrepancy can be accounted for by the larger mesh size of the samplers used by Dr. Pennak (see Zelt and Clifford, 1972). The biomass parameter is probably more indicative of the true condition of the streams bottom faunas, large numbers of small individuals having little effect on the total biomass. Table 4 gives an ordinal breakdown of the data presented in Table 3. From this the relative importance of each order can be figured. The most abundant orders are the Ephemeroptera, Trichoptera, Diptera, and Plecoptera (see Figures 2 and 3). The Diptera at Pacific Creek in figure 2 is not totally indicative of the roll played by this order in the stream. Figure 3 shows large Dipteran biomasses for July 14 and August 9. In both cases the family Tipulidae was responsible for the weight increase. This is not to say that the family did not play a major role in the stream (the genus Hexatoma represented one of the largest Dipteran predators and there were at least 8 other genera filling different roles in the trophic network), but a few individuals biased the percentages markedly.

The major trophic level in the streams (collector, collector-scraper, scraper) is comprised mainly by the Ephemeroptera and secondarily by the Diptera and Trichoptera. The mayfly families Baetidae ( 2 genera, 5 species) Ephemerallidae (1 genus, 7 species), Heptageniidae ( 4 genera, 6 species), Leptophlebiidae (1 genus, 3 species), and Siphlonuridae (2 genera, 2 species) all share this niche (although siphlonurus occidentalis is sometimes an engulfer (Edmunds, 1960). The filterers are represented by the Trichopteran families Brachycentridae ( 2 genera, 3 species) and Hydropsychidae ( 2 genera, 3 species) with the Dipteran family Simuliidae (1 genus, 2 species) forming the only other filtering organism. If the trophic levels were divided according to biomass this group would appear to play a larger role in the streams. The shredders in the stream are mainly Plecoptera in the families Pteronarcidae (2 genera, 2 species), Nemouridae (2 genera, 4 species), and Capniidae 1 species). Some of the Diptera in the family Tipulidae and Trichoptera in the family Lepidostomatidae (1 species) also occupy this trophic level. The actual biomass represented by this group is less than what is shown by division accouding to taxa. This is in juxtaposition to deciduous woodland streams in which this group plays a large role (Cummins, 1974). This group became prevalent in late August and September as would be expected with the increase of allocthonous material entering the streams. The streams predators (engulfers and piercers) are accounted for with Plecoptera in the families Chloroperlidae, Perlidae (2 genera, 2 species), and perlodidae (2 genera, 2 species). The Diptera also contribute to this niche with members of the families Athericeridae (1 species), Tipulidae, Dolichopodidae (2 genera, 2 species), Muscidae ( 2 genera, 2 species), Empididae (2 genera, 2 species), and Chironomidae. This trophic level also has the number of taxa outstripping the comparative biomass. 
The Diptera appear to form the main predators of pools and slower moving areas within the stream. The Plecoptera assume this role in the fast riffle and areas with swifter current. The Plecoptera seemed to play a more significant role in Pacific Creek (as can be inferred from figure 1) than in Pilgrim Creek. The Tipulidae and Chironomidae forming the major predators in Pilgrim Creek. The stonefly Hesperoperla pacifica was a significant engulfer in both streams, but most prevalent in Pacific Creek. A large Perlid predator population can have a significant effect in reducing the standing crop (Siegfried and Knight, 1976). Gut analysis was precluded because of the need to keep whole specimens for biomass measurements. Subsequently all trophic level analys is was taken from the following literature (Merritt and Cummins, 1978; Gilpin and Brusven, 1970; Muttkowski and Smith, 1929; Chapman and Demory, 1963; Edmunds, 1960).

There were not enough samples taken (14/stream) to make statistically significant statements about the spatial distribution of the insects (Resh, 1979). Figure 5 generally reflects the composition of the two streams microhabitats. The Diptera were the most diverse and abundant order in the pool areas of both streams. Members of the order could be found in all trophic levels except the filterer $n i c h e$ which was absent from the pools studied. The medium riffle had the greatest abundance and diversity of Ephemeroptera. This is a reflection of the dense aggregation of epilithic periphyton and allocthonous organic material accumulated on the substrate in this area (see Rabeni and Minshall, 1977). The current excludes Dipterans without special adaptations for sticking to the substrate and the collectorscraper niche filled by the Ephemeroptera is left wide open.

The faunal composition of the fast riffles in the two streams are different, as are their physical properties. The substrate is similar in both streams, as is the current velocity. But, the size of the fast riffle at Pilgrim Creek and the amount of water flowing through it is approximately half that of Pacific Creek. Pacific Creek supports a large population of Hesperoperla pacifica, Pteronarcella badia, several species of Chloroperlidae and some Pteronarcys californica. Pilgrim Creeks fast riffle Plecopteran community is quite reduced in comparing numbers of species and organisms. It seems as though the Trichopteran filterers Arctopsyche grandis and Hydropsyche spp. along with the Dipteran filterer abundance can partially be explained by the increased amount of organic bottom more so than Pacific Creek the fast riffle is preceded by a long stretch of low gradient stream with dense accumulation of "lithophyton" (see Pennak, 1977). In both streams the scouring action of the flow in the fast riffle cleaned most of the epilithic periphyton from the rocks and only large pieces of detritus lodged between the rocks.

\section{Conclusion}

Pilgrim and Pacific Creeks are unpolluted fast-flowing Rocky Mountain trout streams. Both streams are characterized by approximately 2 
months of extremely high discharge due to spring snowmelt, Subsequently the insect faunas have evolved mechanisms to avoid this highly stressfull period of the year (see Good, 1974). The spates reduce the standing crop markedly (Siegfried and Knight, 1977; Anderson and Lemkuhl, 1968) so that spring biomass measurements are the lowest of the year. July through September is a period of recruitment and recolonization for the benthos. Autocthonous material is produced steadily in the post flood stage and appears to be the invertebrates major energy source. This factor sets apart these streams from deciduous woodland streams which depend on allocthonous material for energy (Fisher and Likens, 1973). The trophic structure of the stream is markedly different from woodland streams. The shredders comprise an insignificant proportion of the biomass. The scraper-collector food niche is the largest and most diverse, although most of the representatives are in the Ephemeroptera. Different microhabitats of the stream support specific groups of organisms, Pool areas with sand and gravel substrates contain a diverse ensemble of Dipterans (excluding the filterers). Medium riffles with their large areas of epilithic periphyton covered gravel and cobble support the Ephemeropterans in the scraper-collector trophic level. The fast riffles with boulders, cobble, and gravel harbor the most diverse and abundant arrays of insects in many orders. Generally it appeared as though the fast riffle supported the most species and contained the largest biomass, the pools next largest, and the medium riffles the smallest.

\section{$\underline{\text { Literature Cited }}$}

Allen, J.D. 1975. The distributional ecology and diversity of benthic insects in Cement Creek, Colorado. Ecology 56:1040-1053.

Anderson, N.H. and D.M. Lemkuhl. 1968. Catastrophic drift of insects in a woodland stream. Ecology 49:198-206.

Chapman, D.W. and R. Demory. 1963. Seasonal changes in the food ingested by aquatic insect larvae and nymphs in two Oregon streams. Ecology 44:140-146.

Cummins,K.W. and G.H. Lauff. 1969. The influence of substrate particle size on the microdistribution of stream macrobenthos. Hudrobiologia 34:145-181.

Cummins, K.W. 1974. Structure and function of stream ecosystems. Bioscience 24:631-641.

Davis. 1938. Instructions for conducting stream and lake surveys. Fishery Circ. U.S. Bur. Fish, 26:1-55.

DE March, B.G.E. 1976. Spatial and temporal patterns in macrobenthic stream diversity. J. Fish. Res, Board Can, 33:1261-1270. 
Edmunds, G.F. Jr. 1960. The food habits of the nymph of the mayfly Siphlonurus occidentalis. Proc. Utah Acad. Sci. Arts and Letters. 37:73-74.

Fisher, S.G. and G,E, Likens, 1973. Energy flow in Bear Creek, New Hampshire: an integrative approach to stream ecosystem metabol ism. Ecol. Monogr, 43:421-439,

Gilpin, B.R. and M.A. Brusyen, 1970. Food habits and ecology of mayflies of the St. Maries Ricer in Idaho. Melanderia 4:19-40.

Good, W.R. 1974. Some effects of spring snowmelt runoff on aquatic invertebrates populations in a high mountain stream. Water Resources Series No. 50. Univ, of Wyo., Laramie.

Hurlbert, S.H. 1971. The nonconcept of species diversity: a critique and alternative parameters. Ecology. 52:577-586.

Lind, 0.T. 1974. Handbook of common methods in limnology. C.V. Mosby Co. 154 pps.

Merrit, R.W. and K.W. Cummins (eds.) 1978, An introduction to the aquatic insects of North America. Kendall/Hund Publishing Co, 441 pps.

Muttkowski, R.A. and G.M. Smith. 1929. The food of trout stream insects in Yellowstone National Park. Roosevelt Wildlife Ann. $2: 241-263$.

Pennak, R.W. 1977. Trophic variables in Rocky Mountain trout streams. Arch. Hydrobiol. 80:253-285.

Rabeni, C.F. and G.W. Minshall. 1977. Factors affecting microdistribution of stream benthic insects. 0ikos. 29:33-43.

Rawson, D.S. 1951. The total mineral content of lake water. Ecology. $32: 669-672$.

Reed, J.F, 1952. The vegetation of the Jackson Hole Wildlife Park, Wyoming. Am. Midl. Nat. 48:701-729.

Resh, V.H. 1979. Sampling variability and life history features: basic considerations in the design of aquatic insect studies. $36: 290-311$.

Siegfried, C.A, and A.W. Knight. 1977. The effects of washout in a Sierra foothill stream. Am. Midl. Nat, 98:200-206

Siegfried, C.A, and A.W, Knight, 1976. Trophic relations of Acroneuria (Calineuria) californica (Plecoptera: Perlidae) in a Sierra foothill stream. Envi ronmental Ent. 5:575-581. 
Zelt, K.A. and H.F. Clifford, 1971, Assessment of two mesh sizes for interpreting life cycles, standing crop, and percentage composition of stream insects. Freshw. Bịol, 2:259-269. 